\title{
DIE ONTWIKKELING VAN 'N ORGANISASIE DIAGNOSTIESE VRAELYS
}

\author{
A.M. VERWEY* \\ DEPARTEMENT BEDRYFSIELKUNDE \\ RANDSE AFRIKAANSE UNIVERSITEIT
}

\begin{abstract}
The main objective of this study is the development of a questionnaire which can be used to diagnose the functioning of organisations. Factor-and item analyses confirmed the conceptual model to a large extent. The high degree of internal consistency of the questionnaire, lends at least initial support for the construct validity of the model.
\end{abstract}

Uit navorsing gedoen deur Coetsee et al., (1978) blyk dit duidelik dat daar groot leemtes in organisasie-ontwikkelingsbenaderings in Suid-Afrika is. Spesifiek word die wetenskaplikheid waarmee sulke pogings van stapel gestuur word, ernstig bevraagteken. 'n Uitgangspunt wat hierdie probleem deels kan help oplos, is dat meer inligting genereer behoort te word, op grond waarvan organisasieontwikkeling beplan kan word. Katz en Kahn (1978) gaan van die standpunt uit dat drie vrae gevra moet word wanneer aan ingrepe op organisasies gedink word, naamlik:

- wat is die huidige stand van die organisasie

- $\quad$ wat is die gewensde stand van die organisasie; en

- $\quad$ hoe word vanaf die huidige na die gewensde stand beweeg.

Vir die doeleindes van hierdie studie is daar van die standpunt uitgegaan dat die eerste twee van bogenoemde vrae slegs relatief tot mekaar geëvalueer kan word. Met ander woorde, dit is slegs moontlik om die huidige stand van 'n organisasie te beskryf relatief tot die gewensde stand, en vice versa. Hierdie standpunt impliseer dat daar 'n model van organisasiefunksionering moet bestaan wat die ideale stand van die organisasie aandui, maar wat ook gebruik kan word om die organisasie se huidige stand relatief tot hierdie ideaal te kan diagnoseer. Volgens Bowers et al., (in Hackman et al., 1977) kan so 'n diagnose ook gebruik word om die toepaslikheid van ingrepe aan te dui. Hieruit volg dan dat 'n diagnose van die organisasie se funksionering, gebruik kan word om antwoorde op al drie bogenoemde vrae te

\footnotetext{
* Versoekevir herdrukke moet aan die skrywer gerig word
} 
verskaf, mits so 'n diagnose gebaseer word op 'n model wat organisasiefunksionering konsepsueel omlyn. Die hoofdoelwit van hierdie studie was om 'n vraelys te ontwikkel wat vir so 'n diagnostiese doel gebruik kan word. Die bereiking van hierdie doelwit impliseer egter dat ' $n$ model van organisasiefunksionering as basis vir die vraelys moet dien.

Hoewel verskeie modelle van organisasiegedrag of -funksionering in die literatuur gevind kon word, het hulle almal sekere leemtes. Om hierdie rede is besluit om na die totale veld van organisasieteorie te kyk ten einde kritieke dimensies van organisasiegedrag te identifiseer. Met dieselfde doel voor oë is ook gelet op enkele organisasie-ontwikkelingstegnieke en modelle van organisasiefunksionering.

Uit die bestudering van die klassieke benadering tot organisasiegedrag is dit duidelik dat dit hier om twee hoofdimensies van organisasiegedrag gaan, naamlik spesialisasie van arbeid aan die een kant, en koördinasie (Scott et al., 1981) aan die ander kant. Koördinasie word bereik deur aandag te skenk aan funksionele verdeling, lyn- en staffunksies en die toepassing van die beginsels van spanwydte van beheer (Lewis, 1980).

Die neo-klassieke benadering neem die aannames van die klassieke benadering as gegewe. Twee verdere punte geniet egter ook aandag. Eerstens word die invloed van die individu op arbeidsverdeling en koördinasie beklemtoon (Scott in Hackman et al., 1977) en tweedens word die bestaan en invloed van die informele groep ook in ag geneem (Baird, 1977).

Die sisteembenadering tot organisasiegedrag tipeer die organisasie as 'n oopsisteem (Lewis, 1980) wat in wese ook 'n sosiale sisteem is (Bouling in Scott et al., 1981). Katz en Kahn (Lewis, 1980) dui verder aan dat die organisasie ook 'n inset-omset-uitset sisteem is. Wanneer spesifiek na die omset gedeelte van hierdie benadering gekyk word, word dit gou duidelik dat die organisasie uit sekere elemente en prosesse bestaan (Baird, 1977). Binne die breë raamwerk van die sisteembenadering kan verskillende skrywers se uitgangspunte geïntegreer word om ses elemente van die organisasie te identifiseer, naam1ik die omgewing; tasbare bates; struktuur; interne sosiale sisteem; tegnologie en bestuur. Omgewingsinteraksie, omset en terugvoer is die hoof prosesse wat in die organisasie plaasvind.

Verskillende organisasie-ontwikkelingstegnieke kan, in terme van hul spesifieke fokuspunte, ook binne dieselfde raamwerk beskou en geklassifiseer word as verbandhoudend met organisasieteorie. Tegnieke soos posontwerp (Scanlan, 1973) en doelwitbestuur (French en Bell, 1973) kan byvoorbeeld as behoordend tot die klassieke era beskou word omdat dit 
hoofsaaklik op taakuitvoering fokus. Sensitiwiteitsopleiding (Katz en Kahn, 1978) en spanbou (Podlesnik, 1978) kan weer as neo-klassieke tegnieke beskou word aangesien die fokus daarvan die individu en/of die groep is.

Vanuit die sisteembenaderingshoek beskou, behoort 'n organisasieontwikkelingstegniek op al die substelsels van die organisasie te fokus. Dit omvat dus uiteraard die elemente en prosesse waaruit die organisasie bestaan. Tegnieke wat aan hierdie vereiste voldoen is onder andere proseskonsultasie (Schein, 1969) en ruitekaart organisasie-ontwikkeling (French en Bell, 1973). Die enkele benadering tot organisasie-ontwikkeling wat egter waarskynlik die filosofie onderliggend aan die sisteembenadering tot organisasie die beste weerspieël, is organisasiediagnose. Dit gaan hier in wese om die inwinning, ontleding en terugvoering van inligting binne die raamwerk van 'n organisasie-ontwikkelingsprogram (Nadler, 1977). Omdat die inligting wat ingewin word bruikbaar en geldig moet wees (Argyris in Hackman et al., 1977), moet die diagnose op 'n model van organisasiefunksionering gebaseer word.

Daar bestaan verskeie modelle wat poog om die funksionering van 'n organisasie te vereenvoudig en te verklaar. Wanneer hierdie modelle inhoudelik vergelyk word met die teoretiese benadering tot organisasiegedrag soos hierbo uiteengesit, is daar 'n groot mate van oorvleueling. Aan die ander kant egter is dit so dat feitlik al die modelle sekere leemtes het. Hierdie modelle slaag, ten spyte van die leemtes, tog daarin om die teoretiese benadering aan te vul en op te helder. Die model van Nadler en Tushman (in Hackman et al., 1977) is byvoorbeeld 'n basiese oopsisteem model met inset-, omset-, en uitsetkomponente. Die model van Beer (in Cummings, 1980) plaas aansienlik meer klem op die sosiale dimensie van die organisasie, naamlik omgewingsinteraksie. Kotter (1978) maak in sy model voorsiening vir drie tydduurtes van organisasiefunksionering, naamlik kort-, medium- en langtermyn. Verder plaas hy ook heelwat klem op die interaksie tussen die onderskeie elemente en prosesse van die organisasie. Hoewel hierdie drie modelle in hul basiese benadering 'n hoë mate van ooreenkoms toon, verskil hulle wesenlik van mekaar ten opsigte van die spesifieke aard van die elemente en prosesse van die organisasie wat deur elk beklemtoon word.

Verder is dit so dat nie een van hierdie modelle poog om organisasieklimaat te verklaar of te verduidelik nie. Om hierdie rede is die model van Franklin, wat op die sogenaamde "Stelsels 4" teorie van Likert gebaseer word (Bowers, 1976), ook bestudeer vir die bydraes wat dit kon lewer. Hierdie model bied egter glad nie 'n verklaring vir die aard van totale organisasiefunksionering nie. 
$\mathrm{Na}$ oorweging van al die bydraes vanuit die literatuur, is besluit om die volgende model van organisasiegedrag as basis te gebruik vir die ontwikkeling van die diagnostiese vraelys (Fig. 1).

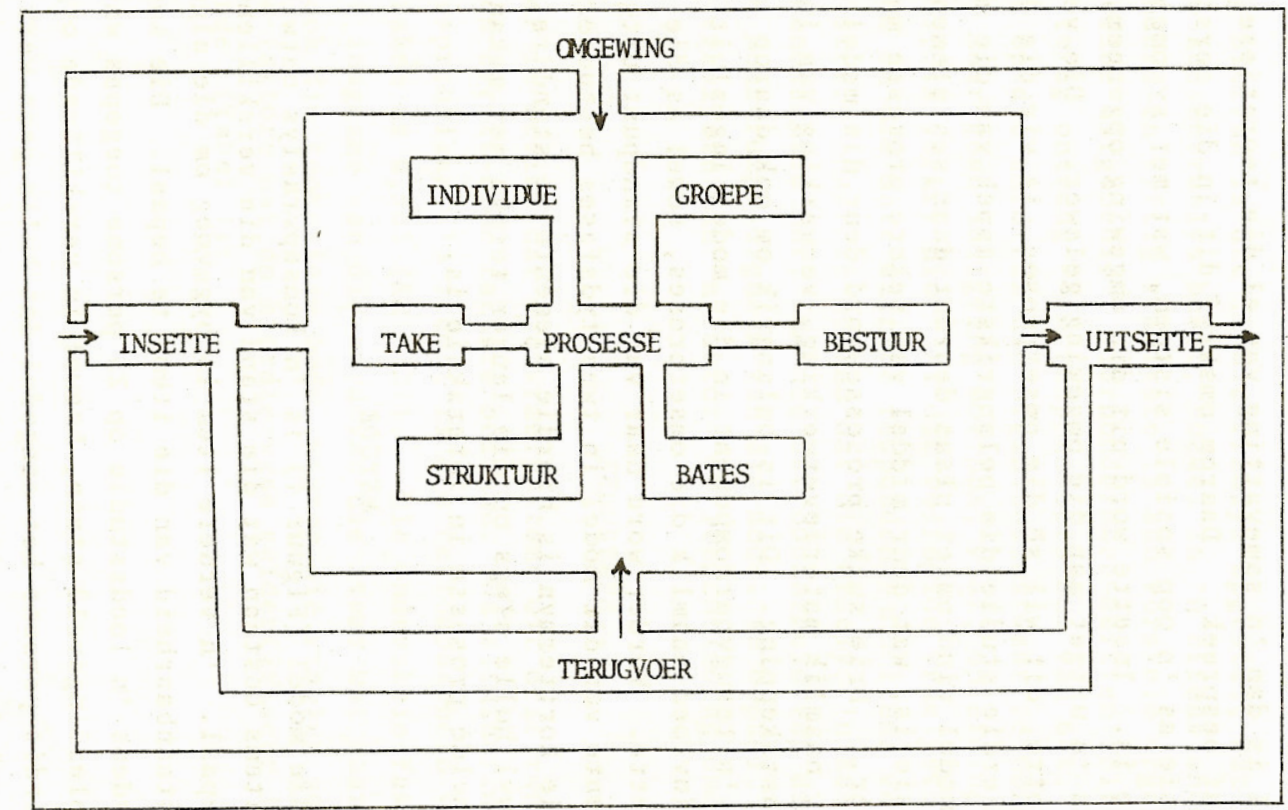

Figuur $1:$ 'n Oopsisteem Organisasie Diagnostiese Mode1

Hierdie model is dan 'n samevatting van al die teoretiese insette soos vooraf bespreek. Daarom omskryf dit in die eerste plek die organisasie as 'n oop sosiale sisteem, wat met sy omgewing in interaksie is. Insette word uit die omgewing opgeneem, en na verwerking as 'n uitset aan die omgewing gelewer. Die verwerking van insette, dit wil sê die omsetproses, is vir die doeleindes van hierdie studie die belangrikste aspek van die model. Volgens die model vind omset plaas deurdat daar ses elemente in die organisasie is, wat deur middel van sekere prosesse met mekaar integreer. Drie sulke prosesse word deur die model voorveronderstel, naamlik materieverwerking, verwerking van inligting en klimaatskepping. Dit is belangrik om ook daarop te let dat daar ook 'n terugvoerkomponent in die model ingesluit word. Terugvoer beïnvloed naamlik die omsetproses, sowel as die opneem van insette. Verder word daar van die standpunt uitgegaan dat die elemente van die model in twee tydsfases bestudeer kan word. Op die korttermyn is hierdie elemente se stand relatief staties, terwyl hulle slegs op die langer termyn met mekaar en die reeds gemelde prosesse in interaksie is. 
Gebaseer op die model (Figuur 1) is 'n konsepvraelys ontwikkel wat uit 115 items bestaan wat die stand van die verskillende subsisteme bepaal. 'n Verdere item is bygevoeg om die algemene vlak van verstaanbaarheid van die items te bepaal. Die konsepvraelys is tydens 'n loodsstudie op 23 persone toegepas wat almal in die opleidingsveld staan, hoewel in verskillende organisasies. Hierdie persone het aangedui dat hulle geen werklike probleme ondervind het om die vraelys te voltooi nie. In die lig hiervan is die finale vraelys opgestel, wat al die items van die konsepvraelys bevat, hoewel in 'n effens ander uitleg. Seshonderd-envyftig vraelyste is aan verskeie organisasies en individue uitgedeel. Vierhonderd-en-dertien voltooide vraelyste is terug ontvang - 'n responskoers dus van $64 \%$. Daar is ook gelet op die aard van die organisasies waar respondente werksaam is, maar geen inligting oor pos, vlak, opleiding, taal, geslag, ens., is verkry nie. Al die voltooide vraelyste is eers ontleed om die mate waartoe respondente die items verstaan het vas te stel. Daar is bevind dat die vraelys ' $n$ hoë mate van verstaanbaarheid het. Om die betroubaarheid van die vraelys en die konstrukgeldigheid van die model te bepaal, is die voltooide vraelyste aan 'n faktor- en itemontleding onderwerp.

\section{RESULTATE}

Daar is bevind dat die vraelysitems uit drie tweede-orde en agtien eerste-orde faktore bestaan. Na eliminering van 22 van die oorspronklike 115 items, is die betroubaarheid van die vraelys bereken as $0,963(\mathrm{KR}-21)$. Die onderskeie faktore is benoem met inagname van die aard van die items wat daaronder groepeer, asook die teoretiese model waarop die vraelys gebaseer is. Die faktore wat op hierdie wyse geïdentifiseer is, is die volgende (Tabel 1): 
TABEL 1

FAKTORE WAARUIT DIE VRAELYS BESTAAN

\begin{tabular}{|l|c|l|}
\hline TWEEDE-ORDE FAKTORE & EIGENWAARDE & FERSTE-ORDE FAKTORE \\
\hline $\begin{array}{l}\text { Interne Organisasie- } \\
\text { funksionering }\end{array}$ & 8,565 & $\begin{array}{l}\text { Onset } \\
\text { K1imaatskepping } \\
\text { Inligting verwerking } \\
\text { Intragroepfunksionering } \\
\text { Individuele funksionering } \\
\text { Departementalisasie } \\
\text { Taakuitvoering } \\
\text { Intergroep funksionering } \\
\text { Individuele funksionering }\end{array}$ \\
\hline Ongewingsinteraksie & $\begin{array}{l}\text { 2,269 } \\
\text { Bestuur }\end{array}$ & $\begin{array}{l}\text { Marktendense } \\
\text { Bronne } \\
\text { Bronbeskikbaarheid } \\
\text { Leweransiers } \\
\text { Uitsette } \\
\text { Deursette } \\
\text { Insette }\end{array}$ \\
\hline
\end{tabular}

\section{GEVOLGTREKKING}

Die vraelys se hoë betroubaarheid word as 'n aanduiding beskou dat die model waarop die vraelys gebaseer word, in 'n hoë mate oor konstrukgeldigheid beskik. Die dimensies van die vraelys toon egter nie deurentyd 'n duidelike verband met die elemente van die model nie. Daar word egter van die standpunt uitgegaan dat hierdie toedrag van sake waarskynlik deur onder andere die volgende verklaar word:

- $\quad$ die interafhanklikheid van en interaksie tussen verskillende substelsels van 'n organisasie maak dit feitlik onmoontlik om hierdie substelsels elkeen afsonderlik of "suiwer" te kan identifiseer; en

- daar moet in ag geneem word dat dit meer as moontlik is dat die vraelysitems nie in alle gevalle die beste meting van spesifieke substelsels gee nie.

Daar word van die standpunt uitgegaan dat die model wat in die studie ontwikkel is, vanuit 'n teoretiese oogpunt gesien, nie as foutief bestempel kan word nie, hoewel dit beslis ook nie as die enigste korrekte, of selfs beste benadering, beskou kan word nie. Die leemte in hierdie studie lê waarskynlik eerder in die ontwikkeling van die vraelys wat op die model gebaseer is, waar die vraelys nie daarin slaag om in die empiriese situasie al die verskillende substelsels van die model te identifiseer nie. In die interpretasie van die navorsingsresultate moet die samestelling van die steekproef egter ook in ag geneem word, aangesien dit in 'n hoë 
mate die faktore en hul samestelling kan beïnvloed. Hier word spesifiek daaraan gedink dat die steekproef nie verteenwoordigend van enige spesifieke organisasie, posgroep, posvlak, ens. is nie.

\section{OPSOMMING}

Die hoofdoel met hierdie studie is die ontwikkeling van 'n vraelys wat vir die diagnose van 'n organisasie se funksionering gebruik kan word. Op grond van 'n oorsig van die literatuur is eers ' $n$ model van organisasiegedrag ontwikkel. Hierdie model dien as basis vir die vraelys wat deur'n steekproef, geneem uit verskeie organisasies, voltooi is. Deur item-en faktorontledings word die aard van die konsepsuele model waarop die vraelys baseer is, in 'n groot mate bevestig. Die hoë interne konstantheid van die vraelys verleen tentatiewe ondersteuning vir die aanname dat die model oor 'n hoë mate van konstrukgeldigheid beskik.

\section{VERWYSINGS}

Argyris, C. The primary task of intervention activities. In Hackman, J.R., Lawler, E.E. III, Porter, L.W. Perspective on behaviour in organizations, New York: McGraw-Hill, 1977.

Baird, J .E. (Jnr.) The dynamics of organizational communication. New York: Harper and Row, 1977.

Beer, M. A social systems model for organization development. In Cummings, T.G. Systems theory for organization development. Chichester: John Wiley, 1980.

Bowers, D.G. Systems of organization: Management of the human resource. Ann Arbor: The University of Michigan Press, 1976.

Bowers, D.G., Franklin, J.L. \& Percorella, P.A. Matching problems, Precursors and interventions in OD: A systemei approach. In Hackman, J.R., Lawler, E.E. III, Porter, L.W. Perspectives on behaviour in organizations. New York: McGraw-Hill, 1977.

Coetsee, L.D., Coster, E.A. \& Van Niekerk, A.M. Die gebruik en doeltreffendheid van organisasie ontwikkeling-tegnieke in 73 groot Suid-Afrikaanse organisasies. Pretoria: Departement Bedryfsielkunde, Unisa, Sept., 1978.

French, W.L. \& Bell, C.H. (Jnr). Organization development: Behavioural science interventions for organization improvement. Englewood Cliffs, New Jersey: Prentice Hall Inc., 1973.

Katz, D. \& Kahn, R.L. The social psychology of organizations. New York: John Wiley, 1978.

Kotter, J.P. Organizational dynamics: Diagnosis and intervention. Reading, Massachusetts: Addison Wesley, 1978.

Lewis, P.V. Organizational communication: The essence of effective management. (Tweede uitgawe). Ohio: Grid Publ. Co., 1980.

Nadler, D.A. Feedback and organization development: Using data-based methods. Reading, Massachusetts: Addison-Wesley, 1977. 
Nadler, D.A. \& Tushman, M.L. A diagnostic model for organizational behavior. In Hackman, J.R., Lawler, E.E. (III), Porter, L.W. Perspectives on behaviour in organizations. New York: McGraw-Hill, 1977.

Podlesnik, R.A. Delphi: An organization development intervention. Ann Arbor: Michigan: University Microfilms International, 1977.

Scanlan, B.K. Principles of management and organizational behaviour. New York: John Wiley, 1972.

Schein, E.H. Process consultation: Role in organization development. Reading, Mass: Addison Wesley, 1969.

Scott, W.E. Organization theory: An overview and an appraisal. In Hackman, J.R., Lawler, E.E. (III), Porter, L.W. Perspectives in behavior in organizations. New York: McGrawHill, 1977.

Scott, W.G., Mitchell, T.R. \& Birnbarum, P.H. Organization theory: A structural and behavioral analysis (vierde uitgawe). Homewood Illinois: Richard D. Irwin, 1981. 